\title{
Author Correction: The Inflammatory Bowel Disease Transcriptome and Metatranscriptome Meta-Analysis (IBD TaMMA) framework
}

Luca Massimino (D), Luigi Antonio LamparelliD, Yashar Houshyar, Silvia D’Alessio, Laurent Peyrin-Biroulet, Stefania Vetrano, Silvio Danese and Federica Ungaro $\mathbb{D}$

Correction to: Nature Computational Science https://doi.org/10.1038/s43588-021-00114-y, published online 20 August 2021.

In the version of this Brief Communication initially published, there were errors in author affiliations. Specifically, affiliation 2 (IBD Center, Humanitas Clinical and Research Center - IRCCS, Rozzano, Milan, Italy) has been corrected to read: "IBD Center, IRCCS Humanitas Research Hospital, Rozzano, Milan, Italy" Further, Luca Massimino was missing a footnote to affiliation 2, while Luigi Antonio Lamparelli's affiliations included affiliation 1 (Department of Biomedical Sciences, Humanitas University, Pieve Emanuele, Milan, Italy) in error. The footnotes have been restored and removed, respectively. The changes have been made to the online version of the article.

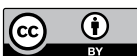

Open Access This article is licensed under a Creative Commons Attribution 4.0 International License, which permits use, sharing, adaptation, distribution and reproduction in any medium or format, as long as you give appropriate credit to the original author(s) and the source, provide a link to the Creative Commons license, and indicate if changes were made. The images or other third party material in this article are included in the article's Creative Commons license, unless indicated otherwise in a credit line to the material. If material is not included in the article's Creative Commons license and your intended use is not permitted by statutory regulation or exceeds the permitted use, you will need to obtain permission directly from the copyright holder. To view a copy of this license, visit http://creativecommons.org/licenses/ by $/ 4.0 \%$.

Published online: 29 September 2021

https://doi.org/10.1038/s43588-021-00146-4

(C) The Author(s) 2021 